\title{
USING AHP FOR DELIBERATIVE MULTICRITERIA-EVALUATION OF FUTURE SCENARIOS
}

\author{
Cornelia R. Karger* \\ Forschungszentrum Jülich GmbH \\ Jülich, Germany \\ E-mail: c.karger@fz-juelich.de
}

\begin{abstract}
The aim of this study ${ }^{1}$ was to design an analytic-deliberative process capable of (1) capturing expert judgments made under conditions of high uncertainty about the relative performance of scenarios to reach sustainability, (2) identifying differences of opinion, and (3) facilitating a reflective formation of preferences on the part of social actors. An expanded deliberative analytic hierarchy process was implemented with the example of four future scenarios for the grid-bound supply of electricity, water and telecommunications in Germany. The assessment of the attribute levels of the scenarios on the discursively obtained hierarchy of sustainability goals was undertaken by eleven scientific experts using an AHP scale coupled with information on judgment confidence. Additionally, their respective justifications were indicated, i.e. the assumptions and hypotheses on which the judgment was based and the scenario elements that were used to make the judgment. Dissent was identified by a systematic classification for the aggregation or non-aggregation of expert judgments. The discursive ranking shows that in spite of divergent expert opinions, the social actors were able to reach convergent judgments on the basis of the AHP judgments supported by the respective justification. Convergence was only impossible if no agreement could be reached on the importance of the respective attribute. Such attributes characterize the line of conflict between the actors which was revealed by the process. The results show that in the case of uncertain and disparate assessments of the degree to which complex options can achieve sustainability, the AHP approach presented here can enable justified decisions.
\end{abstract}

Keywords: deliberation, sustainability, scenarios

\section{Introduction}

Sustainable development is a difficult challenge facing society. On the one hand, there are numerous and often disparate social conceptions as to what should be understood under sustainability. On the other hand, decisions usually have to be made under a high degree of uncertainty. It is often difficult to estimate what ecological, economic and social effects could be associated with different options for the future. This also applies to the organization of grid-bound supply (van Vliet, 2003). The structures of public services with the basic goods of electricity, gas and water, as well as telecommunication services, have become a topic of international debate. The demand for sustainable supply in the future has not just been made in Germany: climate protection measures are being called for; energy carriers such as coal, oil and natural gas are becoming scarce and expensive. At the same time, public utilities in Europe, in particular, must face up to challenges of privatization, the opening of the market and globalization. The cost pressure demands savings. The question arises as to how much scope sustainable development actually has under these conditions.

\footnotetext{
* Corresponding author

${ }^{1}$ The study was funded by the German Federal Ministry of Education and Research (BMBF) as part of the joint research project "Integrated Microsystems for Supply" within the focal framework of "social-ecological research".
} 
"Sustainability" is undisputed in society as a reference framework for shaping the future of supply. Certain proposals for ensuring a sustainable future are already being discussed. Examples include making the supply system more efficient using modern telecommunications or solving the $\mathrm{CO} 2$ problem by encouraging more local energy generation and by using renewable energy sources. However, it is unclear what concrete requirements will have to be satisfied by the sustainability route in the future. The sustainable supply discussion does not just focus on ecological requirements such as climate protection but also on security of supply and economic viability. How important each of the requirements are, however, is often disputed.

Multi-criteria processes are gaining popularity in sustainable energy management (Pohekar and Ramachandran, 2004; Wang et al., 2009). Scenario-based multi-criteria processes are among the latest approaches (Madlener et al., 2007; Karger \& Hennings, 2009). Different future scenarios and the assessment of their consequences are used here as the starting point for decisions on what direction to take. If we take social actors into consideration, then it is their task to formulate what they think is important, for example, in the case of sustainable energy supply. The task of scientific experts, in contrast, is to assess how well or how poorly the various alternative courses of action can fulfil the corresponding objectives. Experts can estimate what consequences each course of action will have, but how significant these actually are is a questions of values. As none of the options can fulfil all of the objectives equally well, the situation must be weighed up, and this is a process that must ultimately be performed by the social actors. In the case of complex and uncertain facts, the difficulty here lies in configuring an analytic-deliberative decision-making process in such a way that the process of weighing everything up accounts for all of the available information and that it also considers the quality of knowledge. In particular, this means that it must be clear to the social actors which statements made by the experts about the impact of certain courses of action are sound and reliable and which are unreliable and incomplete or perhaps even disparate. The objective is to achieve as sound an examination as possible of the objectives and values against the background of alternative courses of action and their consequences. Ultimately, the quality of the decision-making process must be increased. This gives rise to three questions in particular and it is these three questions that this study concentrates on:

○ How can a high degree of reflection be achieved on the judgments?

- How can the performance of the alternatives be ascertained and clearly represented when the information is uncertain and incomplete?

- How can disagreement between the experts be dealt with or indeed how can the social actors reach a convergent overall judgment for divergent expert judgments?

Section 2 describes the conception of the analytic-deliberative process. Section 3 will present examples of the results and conclusions will be drawn in Section 4.

\section{Method}

The empirical study is based on four future scenarios of grid-bound supply for Germany in 2025 . These scenarios are explorative scenarios that were developed in workshops with social actors and scientists from all four sectors of electricity, gas, water and telecommunications (Karger \& Markewitz, 2011).

\subsection{Participants}

A total of eleven scientific experts and twenty-two social actors from Germany participated in the analytic-deliberative process. In terms of expertise, the scientific experts covered all objectives and attributes to be evaluated. The social actors comprised representatives from politics as well as disseminators and decision-makers from relevant social organizations representing both the demand side of supply services and the supply side, together with representatives from environmental and consumer protection agencies and trade unions.

\subsection{Determining objectives and performance of the scenarios}

Objectives and attributes, which were used as the basis for evaluating the four future scenarios, were determined discursively using a value tree analysis (Keeney, 1976). 
The experts were asked to assess the four scenarios for all attributes of the value tree. In order to ensure comparable answer formats and to allow qualitative information to be processed, the attributes levels were determined using pairwise comparison judgments based on the nine-step verbally anchored AHP scale (Saaty \& Vargas, 2000). The experts received feedback on the consistency of their judgments based on the AHP consistency analysis as well as anonymous feedback on the evaluation of the other experts. In an expanded AHP, a) justifications for each judgment and b) details on judgment confidence were also ascertained. The justifications had to be related to the details of the scenario elements, upon which the overall judgment is based, as well as the intensity of their importance and their directional impact. Expert knowledge was elicited within the framework of expert reports and interviews, which were supplemented by a Delphi situation.

\subsection{Information presentation formats for social actors}

In order to make the uncertainty of information transparent, a system was developed for the aggregation and non-aggregation of expert judgments. The AHP judgments of the experts were divided into two groups: (1) In the end, the experts came up with the same ranking or differed only very slightly in the level of their relative evaluations of the scenarios. (2) In the end, the experts came up with a different ranking of the scenarios and showed significant deviations in the level of their relative evaluations and their justifications. These judgments can be characterized using the following criteria:

1. The expert judgments are based on the same scenario factors but weight these differently.

2. The experts base their judgment on the same scenario factors but make different assumptions on their directional impact.

3. The expert judgments are based on different scenario factors.

For convergent expert judgments, the attribute levels for the options calculated from the aggregated pairwise comparison factors and the justifications were summarized in a table. In the case of divergent expert judgments, the attribute levels for the individual pairwise comparison factors of the experts and their respective justifications and judgement confidence were prepared.

\subsection{Weighting of objectives}

The social actors weighted the objectives (a) in individual interviews in a two-stage process of rank and point weighting and (b) discursively in groups within the framework of a workshop. In support of the discursive weighting, divergent judgments were justified in rounds of pair discussions in order to overcome possible misunderstandings and achieve convergence. The combination of the different methods of determination aimed to support the valid recording of the judgments on importance as far as possible. The incremental approach in line with Keeney's "value-focused thinking" (Keeney, 1992) aimed to focus attention on the values and objectives and to avoid decisions being made in advance in favor of certain options.

The submodels "weighting" and "performance of the scenarios" were not intended to be used as a basis for mathematically deriving a ranking order of the scenarios based on individual preference functions. On the contrary, the social actors used expert evaluations on the scenario attribute levels as a basis to work out the pros and cons of a future route on all levels of the objective hierarchy.

\section{Results}

The value tree of a sustainable grid-bound supply comprises five objective categories, which were expressed on the bottom level in a total of 86 attributes. Table 1 shows the attributes per objective category which the social actors considered to be most important with the corresponding scenario performances. The actors achieved consensus here.

The results show that the sustainability objectives that were highly weighted were mainly objectives with convergent expert judgments. Climate protection, in particular, for which the experts were not just in agreement but also extremely confident of their judgment, was very highly weighted. When the scenarios were evaluated by the experts as being much worse in terms of climate protection, this was considered to be a significant weakness. In the weighting across all objective levels, climate protection also featured among the three most important sustainability objectives. 
Table 1. The most important attributes per objective category and scenario (A,B,C,D) with their AHPperformances.

\begin{tabular}{|c|c|c|c|c|c|}
\hline \multirow{2}{*}{$\begin{array}{l}\text { Objective category } \\
\text { Environmental protection }\end{array}$} & Most important attribute & $\mathrm{A}$ & $\mathrm{B}$ & $\mathrm{C}$ & $\mathrm{D}$ \\
\hline & $\begin{array}{l}\text { Reduction in } \mathrm{CO}_{2} \text { emissions } \\
\text { Conservation of raw materials } \\
\text { Conservation of areas/materials } \\
\text { Reduction/accumulation of pollutants in soil } \\
\text { Protection of endangered species }\end{array}$ & $\begin{array}{l}+ \\
+ \\
-\end{array}$ & $\begin{array}{l}+ \\
+\end{array}$ & $\begin{array}{l}- \\
-\end{array}$ & $\begin{array}{l}- \\
+ \\
+\end{array}$ \\
\hline Health protection & $\begin{array}{l}\text { Reduction in air pollutants } \\
\text { Prevention of radioactive radiation } \\
\text { Prevention of contamination in drinking water }\end{array}$ & $\begin{array}{l}+ \\
+ \\
-\end{array}$ & + & $\begin{array}{l}- \\
-\end{array}$ & $\begin{array}{l}- \\
-\end{array}$ \\
\hline Security of supply & $\begin{array}{l}\text { Independence from diminishing resources } \\
\text { Low-cost availability } \\
\text { Fault tolerance } \\
\text { Variety of supply services } \\
\text { Spatial availability } \\
\text { Technological diversity }\end{array}$ & $\begin{array}{l}+ \\
- \\
+\end{array}$ & + & $\begin{array}{l}- \\
+ \\
+\end{array}$ & - \\
\hline & Knowledge of existing technologies & - & & + & + \\
\hline Economic aspects & $\begin{array}{l}\text { Efficiency of goods and services } \\
\text { Employment } \\
\text { Innovativeness } \\
\text { Innovation activities } \\
\text { Investment activities } \\
\text { Cost-effective prices } \\
\text { International competitiveness } \\
\text { Pluralistic market structure }\end{array}$ & + & $\begin{array}{l}- \\
- \\
+ \\
+\end{array}$ & $\begin{array}{l}- \\
- \\
- \\
+\end{array}$ & $\begin{array}{l}+ \\
- \\
-\end{array}$ \\
\hline Social aspects & $\begin{array}{l}\text { Maintenance of social resources } \\
\text { Basic service for everyone } \\
\text { Transparency } \\
\text { Distributive justice } \\
\text { International distributive justice } \\
\text { Participation } \\
\text { Prevention of poverty } \\
\text { Socially acceptable prices }\end{array}$ & $\begin{array}{l}+ \\
+\end{array}$ & $\begin{array}{l}- \\
+ \\
+ \\
+\end{array}$ & $\begin{array}{l}+ \\
- \\
-\end{array}$ & $\begin{array}{l}- \\
-\end{array}$ \\
\hline
\end{tabular}

Note: "+"/ "-": attribute level is more than 0.06 above/below the indifference value (0.25)

Bold: divergent expert judgments in AHP

The system of aggregation and non-aggregation of the expert judgments showed the social actors which attribute levels the experts did not agree on. For example, the experts had very different opinions as to which of the scenarios could provide grid-bound supply services more efficiently and more cost effectively (Table 2). The experts' justifications clearly outlined the scenario factors and hypotheses on which they based their judgment.

In choosing important attributes for each objective category and scenario, the actors agreed on a convergent weighting despite divergent expert judgments in all cases (Table 1). In creating the ranking for the three most important attributes across all objective categories, however, the actors only came to a convergent judgment when convergence was possible in the individual weighting of the attributes.

In cases where sustainable supply was also required to be efficient, the social actors agreed with each other. How the future scenarios were evaluated to this effect may have varied among the experts but their justifications still allowed the social actors to partially or fully agree with one of the experts. In contrast, opinion remained divided on whether the sustainability of grid-bound supply is determined by the cost-effective availability of the services. This antagonism indicated a basic conflict of objectives between the actors. 
Table 2. Disparate assessments of the performance of scenarios.

\begin{tabular}{|c|c|}
\hline & Performance of scenarios \\
\hline & $\begin{array}{c}\text { lower-----------------------------higher } \\
\text { by a factor of------------------- by a factor of } \\
.25----.5------1------2-------4\end{array}$ \\
\hline \multirow{2}{*}{$\begin{array}{l}\text { Efficiency of goods and services } \\
\qquad \begin{array}{l}3 \text { experts } \\
2 \text { different assessments }\end{array}\end{array}$} & $------\mathrm{D}------\mathrm{C}------\mathrm{B}------\mathrm{A}------$ \\
\hline & $\begin{array}{c}-----\mathrm{A}----------------\mathrm{C}------ \\
\mathrm{B}\end{array}$ \\
\hline \multirow{4}{*}{$\begin{array}{l}\text { Low-cost availability } \\
\qquad \begin{array}{l}4 \text { experts } \\
4 \text { different assessments }\end{array}\end{array}$} & $-----\mathrm{A}----\mathrm{B}---------\mathrm{D}----\mathrm{C}-----$ \\
\hline & $\begin{array}{c}-------\mathrm{A}-------------\mathrm{C}-----\mathrm{D}----- \\
\mathrm{B}\end{array}$ \\
\hline & $--\mathrm{D}---------\mathrm{C}--------\mathrm{B}---------\mathrm{A}--$ \\
\hline & \\
\hline
\end{tabular}

Note: The table shows the relative performances of scenarios A to D as derived from the experts' assessments using the AHP paired comparisons method. The performance of each scenario is indicated by its position on a 31-step logarithmic scale. The centre of the scale indicates average performance. The leftmost/rightmost position indicates a performance which is a factor of four lower/higher than average. If two or more scenarios are assigned to the same step on the scale, they appear in a column at that step.

\section{Conclusions}

The problem of the "normativity" of the concept of sustainability must take the social actors into account. The matter involves subjective and often disparate target and value assumptions in a society, which ultimately lie beyond scientific decidability. As a result, decisions on what direction to take have specific requirements in terms of the decision-making process. Social actors require a transparent and thus comprehensible and relevant decision-making basis in order to make a reflected and justified judgment. A good decision "requires a process for integrating facts and values in relevant analysis and a constructive deliberative exchange" (Gregory et al., 2006, p.720).

The expanded deliberative hierarchy process shows how expert judgments on the performance of complex future options can be recorded and prepared in such a way that social actors can understand them and thus make justified judgments. Despite disagreement among the experts, the social actors were still able to make convergent judgments. This also applied when opinion on the importance of an attribute was initially divergent. Where differences could be largely reconciled in a reflected examination of each of the relevant objectives and their weighting, it was possible to come to a common conclusion on the basis of the expert justifications.

In the case of uncertain and disparate evaluations of the consequences of alternative courses of action for sustainable development, a reflected decision-making process was supported by (a) AHP expert judgments and (b) a system of aggregation revealing differences between the experts.

\section{REFERENCES}

Gregory, R., Failing, L., Ohlson, D., McDaniels, T.L. (2006): Some pitfalls of an overemphasis on science in environmental risk management decisions. Journal of Risk Research, 9 (7), 717-735. 
Karger, C.R. \& Hennings, W. (2009): Sustainability evaluation of decentralized electricity generation. Renewable and Sustainable Energy Reviews, 13 (3), 583-593.

Karger, C.R. \& Markewitz, P. (2011): Will energy infrastructure systems in Germany be more decentralized in the future? A participatory scenario process. Innovative Energy Policies (submitted for publication).

Keeney, R. L., \& Raiffa, H. (1976): Decisions with Multiple Objectives. Preferences and valuetradeoffs. New York: Wiley.

Lund H. \& Østergaard P.A. (2000): Electric grid and heat planning scenarios with centralised and distributed sources of conventional, CHP and wind generation. Energy 25, 299-312.

Madlener R., Kowalski, K. and Stagl, S. (2007): New ways for the integrated appraisal of national energy scenarios: The case of renewable energy use in Austria. Energy Policy, 35, 6060-6074.

Pohekar, S.D. \& Ramachandran, M. (2003): Application of multi-criteria decision making to sustainable energy planning - a review. Renewable \& Sustainable Energy Reviews, 8, 365-381.

Saaty T.L, Vargas L.G. (2000): Models, Methods, Concepts \& Applications of the Analytic Hierarchy Process. Boston: Kluwer.

van Vliet, B. (2003), Differentiation and Ecological Modernization in Water and Electricity Provision and Consumption. Innovation: The European Journal of Social Science Research, 16 (1), 29 - 49.

Wang, J-J., Jing, Y-Y., Zhang, C-F. and Zhao, J-H. (2009): Review on multi-criteria decision analysis aid in sustainable energy decision-making. Renewable \& Sustainable Energy Reviews, 13 (9), 2263 2278. 